\title{
Publisher Correction: Enhanced generation and anisotropic Coulomb scattering of hot electrons in an ultra-broadband plasmonic nanopatch metasurface
}

\author{
Matthew E. Sykes ${ }^{1}$, Jon W. Stewart (10 2 ${ }^{2}$, Gleb M. Akselrod ${ }^{2}$, Xiang-Tian Kong (1) 3,4, Zhiming Wang ${ }^{3}$, \\ David J. Gosztola1, Alex B.F. Martinson (D) ${ }^{5}$, Daniel Rosenmann', Maiken H. Mikkelsen (1) 2,6, \\ Alexander O. Govorov (D) ${ }^{4} \&$ Gary P. Wiederrecht ${ }^{1}$
}

Nature Communications 8:986 10.1038/s41467-017-01069-3; Article published online: 17 October 2017

The originally published version of this Article contained an error in Equation 1 . The two $\hbar$ terms were missing from this equation, which incorrectly read:

$$
\text { Rate }_{\text {nonthermal }}=\sum_{i=\mathrm{Ag}, \mathrm{Au}} \frac{2 e^{2} E_{\mathrm{F}, i}^{2}}{\pi^{2}(\omega)^{3}} \int_{S_{\mathrm{NC}, i}}\left|E_{\mathrm{n}}(\theta, \varphi)\right|^{2} \mathrm{~d} S,
$$

The correct form of Equation 1 is as follows:

$$
\text { Rate }_{\text {nonthermal }}=\sum_{i=\mathrm{Ag}, \mathrm{Au}} \frac{2 e^{2} E_{\mathrm{F}, i}^{2}}{\pi^{2} \hbar(\hbar \omega)^{3}} \int_{S_{\mathrm{NC}, i}}\left|E_{\mathrm{n}}(\theta, \varphi)\right|^{2} \mathrm{~d} S,
$$

This has now been corrected in the PDF and HTML versions of the Article.

Published online: 12 December 2017

Open Access This article is licensed under a Creative Commons Attribution 4.0 International License, which permits use, sharing, adaptation, distribution and reproduction in any medium or format, as long as you give appropriate credit to the original author(s) and the source, provide a link to the Creative Commons license,
and indicate if changes were made. The images or other third party material in this article are included in the article's Creative Commons license, unless indicated otherwise in a credit line to the material. If material is not included in the article's Creative Commons license and your intended use is not permitted by statutory regulation or exceeds the permitted use, you will need to obtain permission directly from the copyright holder. To view a copy of this license, visit http://creativecommons.org/licenses/by/4.0/.

(C) The Author(s) 2017

\footnotetext{
${ }^{1}$ Center for Nanoscale Materials, Argonne National Laboratory, Argonne, IL 60439, USA. ${ }^{2}$ Department of Electrical and Computer Engineering, Duke University, Durham, NC 27708, USA. ${ }^{3}$ Institute of Fundamental and Frontier Sciences and State Key Laboratory of Electronic Thin Films and Integrated Devices, University of Electronic Science and Technology of China, Chengdu 610054, China. ${ }^{4}$ Department of Physics and Astronomy, Ohio University, Athens, OH 45701, USA. ${ }^{5}$ Materials Science Division, Argonne National Laboratory, Argonne, IL 60439, USA. ${ }^{6}$ Department of Physics, Duke University, Durham, NC 27708, USA. Correspondence and requests for materials should be addressed to M.H.M. (email: m.mikkelsen@duke.edu) or to A.O.G. (email: govorov@ohio.edu) or to G.P.W. (email: wiederrecht@anl.gov)
} 